\title{
116. Estimation of Adenohypophyseal Growth Hormone Content in the Diabetic "KK" Mouse Strain by Acrylamide Gel Electrophoresis
}

\author{
By Mitsuo NaKamura \\ Department of Anatomy, Nagoya University, School of Medicine \\ (Comm. by Taku KomaI, M.J.A., May 12, 1966)
}

Since the discovery of diabetic KK strain of mouse by the author (Nakamura 1962), several papers (Nakamura and Yamada 1963, Nakamura 1965, Nakamura and Yamada 1965, Yamada 1966) have been published on the genetics, histology and cytology of the strain. Of those papers, the most recent one (Yamada 1966) dealt with the light- and electron-microscopic studies of the adenohypophysis. By this study some histological evidence for the hypertrophy of the pituitary tissues and the hyperelavoration and abundance of growth hormone $(\mathrm{GH})$ in the KK strain was obtained. To confirm the latter point, a biochemical study was made.

Since Davis and Ornstein's (1959) disc electrophoresis on acrylamide gel method which were applied to the identification of pituitary proteinaceous hormones by Lewis, Cheever, and Vanderlaan (1965) seemed to be a relatively easy technique, and feasible even by researchers other than biochemists, the author used it for an approximate estimation of the $\mathrm{GH}$ content of the $\mathrm{KK}$ mouse hypophysis.

Material and Methods. All the animals used in this study (27 $\mathrm{KK}$ and $22 \mathrm{C57BL}$ control mice) were three-month old males reared on free access to food and water under constant temperature $\left(24^{\circ} \mathrm{C}\right)$ and illumination (from 8 a.m. to 7 p.m.). For the measurement of the organ weight, $7 \mathrm{KK}$ and 7 C57BL mice were sacrificed, and their anterior pituitary lobes were isolated from the posterior lobes. After being dried for three hours at $50^{\circ} \mathrm{C}$, the glands were weighed on a Shimazu automatic chemical balance.

The remainder, $20 \mathrm{KK}$ and $15 \mathrm{C} 57 \mathrm{BL}$ animals, were used for the electrophoretic hormone research. Three adenohypophyses of KK mice were pooled, and homogenized with $0.1 \mathrm{ml}$ ion-deprived water, while four glands of C57BL mice were subjected to the same treatment. The reason why three and four glands were gathered together respectively from $\mathrm{KK}$ and the control mice was that 3 adenohypophyses of the former strain are approximately equal in weight to 4 corresponding organs of the latter strain as to be shown below. The homogenate was centrifuged for ten minutes at about $5000 \mathrm{G}$, and the supernatant 
was electrophoretically separated on acrylamide gel. The preparation of the gel was carried out according to Ogita's improved formula (Ogita 19-65) shown below:

a) ion-deprived water $\ldots \ldots \ldots \ldots \ldots \ldots \ldots \ldots . \ldots 6 \mathrm{cc}$

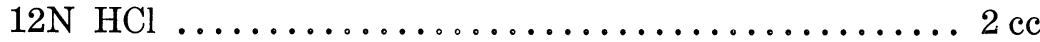

trishydroxymethyl-aminomethane ............. $18.25 \mathrm{~g}$ acrylamide ........................... $19.00 \mathrm{~g}$

$\mathrm{N}, \mathrm{N}^{\prime}$-methylenebisacrylamide $\ldots \ldots \ldots \ldots \ldots \ldots . \ldots 1.000 \mathrm{~g}$

b) $\mathrm{N}, \mathrm{N}, \mathrm{N}^{\prime}, \mathrm{N}^{\prime}$-tetramethylethylenediamine ......... $0.25 \mathrm{cc}$ ion-deprived water ........................ $50 \mathrm{cc}$

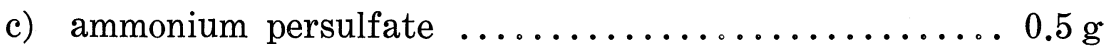
ion-deprived water ...................... $50 \mathrm{cc}$

d) ion-deprived water ........................ $14 \mathrm{cc}$

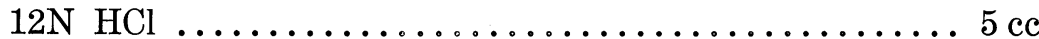
trishydroxymethyl-aminomethane .............. $7.5 \mathrm{~g}$ $\mathrm{N}, \mathrm{N}, \mathrm{N}^{\prime}, \mathrm{N}^{\prime}$-tetramethylethylenediamine .......... $3.0 \mathrm{cc}$

e) ion-deprived water...................... $9.0 \mathrm{cc}$ acrylamide ........................... $10 \mathrm{~g}$ $\mathrm{N}, \mathrm{N}^{\prime}$-methylenebisacrylamide $\ldots \ldots \ldots \ldots \ldots \ldots \ldots 2.5 \mathrm{~g}$

f) riboflavine........................ $4.0 \mathrm{mg}$ ion-deprived water ...................... $50 \mathrm{cc}$

Prior to use, the above solutions were mixed in the following ratio.

1) running gel; a: b: $c=2: 1: 1$

2) spacer ger; d: e: $f$ : ion-deprived water $=0.25: 0.5: 0.25: 9$

3) sample gel; d: e: f: sample (supernatant) $=0.25: 0.5: 0.25: 9$

Plastic columns instead of glass columns were used. After electrophoresis (electric field :300 volts, duration :4 hours, temperature $: 5^{\circ} \mathrm{C}$ ), the gel was removed from the plastic column and stained with amidoblack-B.

Table I. Measurements of the weight of anterior lobes of pituitaries of $\mathrm{KK}$ and $\mathrm{C57BL}$ mice

\begin{tabular}{cccc}
\hline KK mouse & Organ weight $(\mathrm{mg})$ & C57BL mouse & Organ weight $(\mathrm{mg})$ \\
\hline I & 0.4 & I & 0.4 \\
II & 0.5 & II & 0.4 \\
III & 0.5 & III & 0.3 \\
IV & 0.6 & IV & 0.2 \\
V & 0.4 & V & 0.3 \\
VI & 0.4 & VI & 0.4 \\
VII & 0.4 & VII & 0.3 \\
\hline Average & $0.457 \pm 0.029$ & & $0.328 \pm 0.028$ \\
\hline Difference & $0.129 \pm 0.040$ & \\
\hline
\end{tabular}


Results. 1. Measurement of organ weight. As shown in Table I, the adenohypophysis of $\mathrm{KK}$ mice is generally heavier than that in the C57BL mice, and this difference is highly significant. Thus, adenohypophyses of three KK mice are roughly comparable in weight to four corresponding organs of C57BL mice.

2. Examination by means of electrophoresis. In both the strains of mice examined, disc electrophoresis of anterior pituitary extracts revealed such protein pattern as illustrated in Fig. 1. Among three distinct bands noticed, the most slowly migrating band showed a striking difference between KK and C57BL strains, namely, the former's bands were distinctly more intense and broader. Faster migrating two bands, on the contrary, revealed difference neither in density nor in width between the two strains.

Discussion. By the present study, the author has confirmed that the adenohypophysis of the KK mice is heavier than that of the C57BL mice. This result is consistent with Yamada's observation (Yamada 1966) that the gland is apparently larger in the former mice than in the latter.

In the electrophoresis of the anterior pituitary extracts, the most slowly migrating protein band is more densely stained and broader in $\mathrm{KK}$ mice than the corresponding band in C57BL animals. According

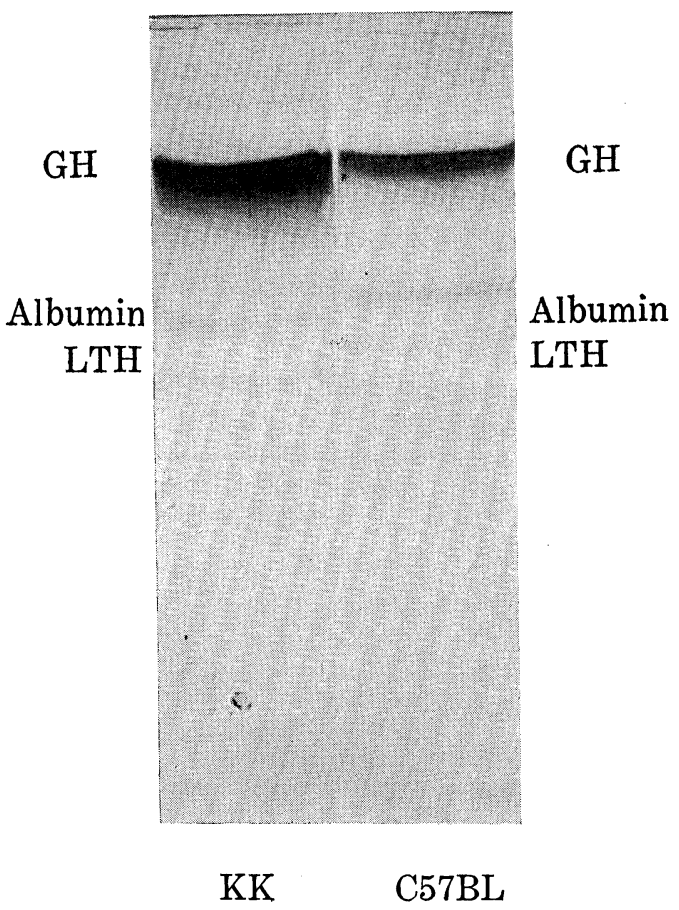

Fig. 1 
to Lewis, Cheever, and Vanderlaan (1965a), this band corresponds to growth hormone $(\mathrm{GH})$. Accordingly, the above finding is interpreted as demonstrating an excess production of pituitary $\mathrm{GH}$ in $\mathrm{KK}$ mice. Thus, the presumption deduced from the histological finding and considered to play an important role in the causation of diabetic trait peculiar to $\mathrm{KK}$ strain mice, is biochemically sustained. However, no difference was found with respect to the remaining two bands between the two strains. According to Lewis, Cheever, and Vanderlaan (1965b) and Jones, Fisher, Lewis, and Vanderlaan (1965), the most anodal band and the intermediate band respectively represent lactogenic hormone (LTH) and serum albumine. This finding suggests that the LTH content in the KK mouse adenohypophysis is almost identical to that in the same gland of the C57BL mouse.

Summary. The weight and protein patterns of anterior pituitary glands obtained from KK and C57BL (control) mice were comparatively examined; the results obtained are as follows:

1. The adenohypophysis of the KK mouse is heavier than that of C57BL mouse.

2. In acrylamide gel electrophoresis, the protein band corresponding to $\mathrm{GH}$ appears more intense in the KK mouse than in the C57BL mouse.

These findings are interpreted in relation to the diabetic trait of the $\mathrm{KK}$ strain mouse.

Acknowledgement. The author wishes to express his sincere appreciation to Prof. Dr. Kazumaro Yamada for his guidance and encouragement.

\section{References}

1) Davis, B. J., and L. Ornstein (1959): "A new high resolution electrophoresis method" delivered at The Society for the Study of Blood, March 24, 1959 at the New York Academy of Medicine, cited from Ogita (1965).

2) Jones, A., J. Fisher, J. Lewis, and W. Vanderlaan (1965): Electrophoretic comparison of pituitary glands from male and female rats. Endocrinology, 76, 578-583.

3) Lewis, J., E. Cheever, and W. Vanderlaan (1965a): Studies on the growth hormone of normal and dwarf mice. Endocrinology, 76, 210-215.

4) - (1965b): Alteration of the proteins of the pituitary gland of the rat by estradiol and cortisol. Endocrinology, 76, 362-368.

5) Nakamura, M. (1962): A diabetic strain of the mouse. Proc. Japan Acad., 38, 348-352.

6) (1965): Cytological and histological studies on the pancreatic islets of a diabetic strain of the mouse. Zeitschrift für Zellforschung, 65, 340-349.

7) Nakamura, M., and K. Yamada Jr. (1963): A further study of the diabetic (KK) strain of the mouse. $F_{1}$ and $F_{2}$ offspring of the cross between $\mathrm{KK}$ and C57BL/6 mice. Proc. Japan Acad., 39, 489-493.

8) - (1965): Enzymorphological studies on the pancreatic islets of a diabetic 
(KK) strain of the mouse. Zeitschrift für Zellforschung, 66, 396-404.

9) Ogita, Z. (1965): Disc electrophoresis. Metabolism and Disease, 2, 419-435.

10) Yamada, K. Sr. (1966 in press): Light and electron microscopic studies on the adenohypophysis of a diabetic (KK) strain of the mouse. 